\title{
Chronic creatine kinase deficiency eventually leads to congestive heart failure, but severity is dependent on genetic background, gender and age
}

\author{
Craig A. Lygate $\cdot$ Debra J. Medway $\cdot$ Philip J. Ostrowski • \\ Dunja Aksentijevic $\cdot$ Liam Sebag-Montefiore $\cdot$ Imre Hunyor • \\ Sevasti Zervou $\cdot$ Jurgen E. Schneider $\cdot$ Stefan Neubauer
}

Received: 10 May 2012/Revised: 2 June 2012/ Accepted: 13 June 2012/Published online: 4 July 2012

(C) The Author(s) 2012. This article is published with open access at Springerlink.com

\begin{abstract}
The creatine kinase (CK) energy transport and buffering system supports cardiac function at times of high demand and is impaired in the failing heart. Mice deficient in muscle- and mitochondrial-CK (M/Mt- $\mathrm{CK}^{-/-}$) have previously been described, but exhibit an unexpectedly mild phenotype of compensated left ventricular (LV) hypertrophy. We hypothesised that heart failure would develop with age and performed echocardiography and LV haemodynamics at 1 year. Since all previous studies have utilised mice with a mixed genetic background, we backcrossed for $>10$ generations on to $\mathrm{C} 57 \mathrm{BL} / 6$, and repeated the in vivo investigations. Male $\mathrm{M} / \mathrm{Mt}_{-} \mathrm{CK}^{-1-}$ mice on the mixed genetic background developed congestive heart failure as evidenced by significantly elevated end-diastolic pressure, impaired contractility, LV dilatation, hypertrophy and pulmonary congestion. Female mice were less severely affected, only showing trends for these parameters. After backcrossing, M/Mt-CK ${ }^{-1-}$ mice had LV dysfunction consisting of impaired isovolumetric pressure changes and reduced contractile reserve, but did not develop congestive heart failure. Body weight was lower in knockout mice as a consequence of reduced total body fat. LV weight was not
\end{abstract}

Electronic supplementary material The online version of this article (doi:10.1007/s00395-012-0276-2) contains supplementary material, which is available to authorized users.

C. A. Lygate $(\varangle) \cdot$ D. J. Medway · P. J. Ostrowski

D. Aksentijevic $\cdot$ L. Sebag-Montefiore $\cdot$ I. Hunyor ·

S. Zervou - J. E. Schneider · S. Neubauer

Department of Cardiovascular Medicine, Wellcome Trust Centre

for Human Genetics, University of Oxford, Roosevelt Drive,

Oxford OX3 7BN, UK

e-mail: clygate@well.ox.ac.uk significantly elevated in relation to other internal organs and gene expression of LVH markers was normal, suggesting an absence of hypertrophy. In conclusion, the consequences of CK deficiency are highly dependent on genetic modifiers, gender and age. However, the observation that a primary defect in CK can, under the right conditions, result in heart failure suggests that impaired CK activity in the failing heart could contribute to disease progression.

Keywords Creatine kinase - Cardiac energetics . Heart failure - Energy metabolism - Transgenic mice

\section{Introduction}

Creatine kinase (CK) is the major phosphotransfer system in the heart linking energy production to energy utilisation. Mitochondrial-CK (Mt-CK) catalyses the transfer of a phosphoryl group from ATP to creatine to form phosphocreatine (PCr), which transports energy within the cell and acts as a short-term energy buffer, available for rapid regeneration of ATP at times of suddenly increased workload. This reverse reaction is catalysed by cytosolic CK dimers, consisting of muscle- (M-CK) and brain(B-CK) isoforms, with the MM-CK isoenzyme by far the most prevalent $[12,32]$.

Down-regulation of the CK system is a hallmark of heart failure regardless of aetiology [29]. For example, total creatine is reduced by up to $56 \%$ [18] and CK activity by up to $48 \%$ [33], and low PCr/ATP ratio is a predictor of mortality in patients with dilated cardiomyopathy [20], contributing to the hypothesis that the failing heart is energy starved [19]. Understanding how such changes impact on pathophysiology may inform new therapeutic 
approaches, and in support of this, over-expression of $\mathrm{M}-\mathrm{CK}$ has recently been shown to protect mice from heart failure due to pressure overload [11], suggesting CK changes are not simply an epiphenomenon.

One approach is to study mice with genetic deletion of key components of the CK system and then determine the effect on cardiac phenotype in vivo. At the simplest level, overt dysfunction would indicate potential for a causative role in the progression to heart failure, but in practice, interpretation of knockout models is often obfuscated by physiological redundancy and compensatory adaptations [2]. CK knockout strains have been created for M-CK, Mt-CK and the combined double gene deletion [25, 27], and have proven to be no exception. Loss of M-CK ( $\sim 50 \%$ of total $\mathrm{CK}$ activity) results in a very mild phenotype with no overt left ventricular hypertrophy $(\mathrm{LVH})$ or dysfunction apparent [16, 28, 30]. The double $\mathrm{KO}\left(\mathrm{M} / \mathrm{Mt}^{-} \mathrm{CK}^{-1-}\right)$ has a more robust cardiac phenotype, which is broadly similar to the single $\mathrm{Mt}_{-} \mathrm{CK}^{-1-}$, suggesting that loss of Mt-CK rather than up to $98 \%$ loss of total creatine kinase activity is the driving force [16, 22, 24]. Compensated LVH has been observed in most studies $[13,16,17]$ (although not in all [22, 24]), and likewise functional defects have not always been evident [22] or relate only to impaired contractile reserve [7]. Even at 41 weeks of age, there were no differences in MRI parameters of global function [16], but only subtle changes in perfusion and ejection times [17]; remarkably, these mice could survive experimental myocardial infarction [16].

However, a number of question marks remain concerning the in vivo cardiac phenotype of the M/Mt- $\mathrm{CK}^{-/-}$ mice. Firstly, it is not known whether LVH will eventually progress to heart failure if studied beyond 41 weeks of age. Secondly, LV haemodynamic measurements have never been obtained in vivo, but only at much lower workloads in Langendorff preparations. Thirdly, all studies to date have used mice on a mixed C57BL/6 and 129Sv genetic background. We have previously shown this to be critically important in $\mathrm{Mt}-\mathrm{CK}^{-/-}$mice, where backcrossing to a pure BL/6 background resulted in loss of the LVH phenotype [15]. In the current study we address all of these points. We demonstrate for the first time that $\mathrm{M} / \mathrm{Mt}-\mathrm{CK}^{-/-}$mice on the standard mixed background eventually develop congestive heart failure by 1 year of age. We then characterise a backcrossed strain of $\mathrm{M} / \mathrm{Mt}-\mathrm{CK}^{-1-}$ on a pure $\mathrm{BL} / 6$ background and show this to have defects in isovolumetric contraction/relaxation and reduced body fat, but to no longer develop LVH or congestive heart failure. Our findings show for the first time that a chronic primary defect in creatine kinase ultimately results in congestive heart failure, but that severity of dysfunction is influenced by sex and genetic modifiers.

\section{Methods}

Mouse colonies

Creatine kinase double knockout mice (i.e. deficient in both $\mathrm{M}-\mathrm{CK}$ and mitochondrial-CK isoenzymes) were imported from a colony at the University of Würzburg, which in turn originated from the laboratory of Prof Wieringa (University of Nijmegen, The Netherlands) [25, 27]. These represent the standard strain reported in the literature, which are on a non-fixed mixed C57BL/6 and 129Sv genetic background and are therefore denoted M/Mt-CK ${ }^{-/-(129 / \mathrm{B} 16)}$ in this manuscript. These mice were used for breeding followed by initial echocardiography and haemodynamic studies reported in Fig. 1, with stock C57BL/6 mice used as control.

Female heterozygotes were backcrossed in our laboratory for ten generations with male $\mathrm{C} 57 \mathrm{BL} / 6 \mathrm{~J}$ mice obtained from Harlan UK to produce $\mathrm{M}-\mathrm{CK}^{-1-}$ and $\mathrm{M} / \mathrm{Mt}-\mathrm{CK}^{-1-}$ mice on a pure genetic background. These mice were produced by heterozygous mating, so that littermates could be used as the appropriate wild-type controls (WT). All investigations were performed when mice were approximately 1-year-old. Mice were kept under specific pathogen-free conditions in individually ventilated cages with 12-h light-dark cycle, controlled temperature $\left(20-22{ }^{\circ} \mathrm{C}\right)$, and fed standard chow and water ad libitum. This investigation conforms with UK Home Office Guidance on the Operation of the Animals (Scientific Procedures) Act, 1986.

\section{Echocardiography}

Mice were anaesthetised with $4 \%$ isoflurane in medical oxygen and maintained on a nose-cone at 1-1.5\%. They were placed supine on a homoeothermic mat, chest fur shaved and parasternal short and long-axis images obtained. M/Mt-CK ${ }^{-/-(129 / B 16)}$ mice were imaged with an Agilent Sonos 5500 equipped with a 7/15 MHz linear-array transducer, while all subsequent imaging was obtained under identical conditions using a Visualsonics Vevo 2100 with 22-55 MHz transducer.

Left ventricular haemodynamics

Approximately 1 week after echocardiography, mice were anaesthetised with $4 \%$ isoflurane in medical oxygen and maintained on a nose-cone at $1-1.5 \%$ on a homoeothermic mat. The left ventricle was cannulated via the right carotid artery using a 1.4-F Millar Mikro-Tip cannula (SPR-839, Millar Instruments, Houston, Texas). The right jugular vein was cannulated with stretched polyethylene tubing for 
Fig. 1 At 1-year of age, M/Mt$\mathrm{CK}^{-/-(129 / \mathrm{B} 16)}$ mice on a mixed genetic background ( $\mathrm{dKO}$ ) develop left ventricular (LV) hypertrophy and dysfunction. LV hypertrophy is significant regardless of whether C57BL/6 or $129 \mathrm{SV}$ is used as control strain, and occurs in both males and females (Panel a). Panels $\boldsymbol{b}-\boldsymbol{e}$ are from males only $(n=5-7$, C57BL/6; $n=6-9$, $\mathrm{dKO}$ ) and indicate significant $\mathrm{LV}$ dilatation in $\mathrm{KO}$ mice measured by echocardiography (b); impaired LV contractility (c) and elevated end-diastolic pressure (d) by in vivo haemodynamics; and pulmonary congestion in $\mathrm{dKO}$ mice at post-mortem (e). Values are mean $\pm \mathrm{SD}$
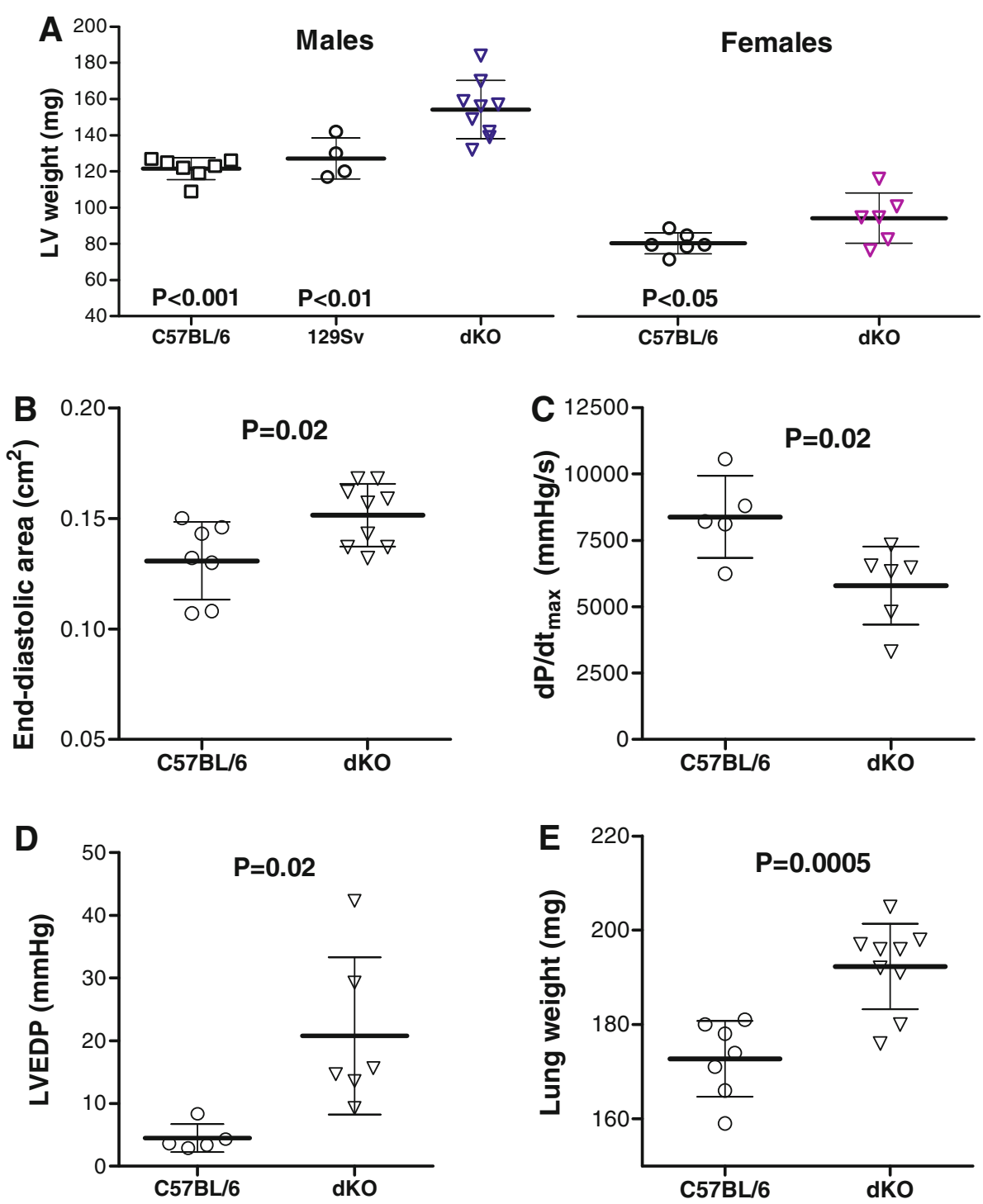

infusion of dobutamine ( $16 \mathrm{ng} / \mathrm{g}$ body weight/min) to test contractile reserve. Measurements were obtained after 15 min of equilibration via a Powerlab 4SP data acquisition system (ADInstruments, UK). At the end of the experiment, the heart and other organs were excised, washed in heparinised saline, blotted and weighed. Left ventricular samples were snap frozen in liquid nitrogen and stored at $-80{ }^{\circ} \mathrm{C}$.

\section{Body composition}

Body composition analysis was carried out by non-invasive magnetic resonance relaxometry in conscious restrained mice using an EchoMRI-100 system (Active Field Resources, Houston, Texas). Accumulation factor was for extra-high precision $(3 \times)$ resulting in a scan time of approximately $2.5 \mathrm{~min}$.
Biochemical and molecular measurements

Total creatine and total CK, CK isoenzyme and citrate synthase activities were measured from LV homogenates as previously described [21]. The activity of total adenylate kinase (AK) was quantified spectrophotometrically as described in [1]. Total RNA was extracted from LV tissue and gene expression of LVH markers quantified using realtime RT-PCR as previously described [15].

Data analysis and statistics

All data were analysed blind to genotype by a single experienced operator. Data are expressed as mean \pm standard deviation throughout. Comparison between two groups was by student's $t$ test, and between three groups by one-way analysis of variance (ANOVA) using 
Bonferroni's correction for multiple comparisons. Differences were considered significant when $P<0.05$.

\section{Results}

In vivo cardiac phenotype of standard mixed background CK double knockout mouse

All previously published studies have reported on M/Mt$\mathrm{CK}^{-/-(129 / \mathrm{B} 16)}$ mice with a mixed $\mathrm{C} 57 \mathrm{BL} / 6$ and $129 \mathrm{~Sv}$ genetic background. When these are maintained by $\mathrm{KO} \times \mathrm{KO}$ breeding, there is no appropriate littermate control, and standard C57BL/6 mice have historically been used for this purpose. However, there are reported differences between C57BL/6 and 129Sv strains for blood pressure and LV mass [8], so we sought to recapitulate the finding of $\mathrm{LV}$ hypertrophy in $\mathrm{M} / \mathrm{Mt}^{-} \mathrm{CK}^{-/-(129 / \mathrm{B} 16)}$ mice under our own standard laboratory conditions and to determine whether choice of control had any influence on the results obtained. Furthermore, we performed in vivo LV haemodynamic measurements, which have never previously been reported for M/Mt-CK ${ }^{-/-(129 / B 16)}$ mice.

At $1+$ years of age (mean 58 weeks), male M/Mt$\mathrm{CK}^{-1-(129 / \mathrm{B} 16)}$ mice had significantly higher $\mathrm{LV}$ weight despite lower body weight and regardless of whether
C57BL $/ 6 \quad(+27 \% ; \quad P<0.001)$ or $129 \mathrm{~Sv} \quad(+21 \%$; $P<0.01$ ) were used as controls (Fig. 1a). This difference was still evident after desiccation, suggesting it was not due to oedema (LV dry weight: $31 \pm 2$ in C57BL/6 versus $38 \pm 6 \mathrm{mg}$ in $\mathrm{M} / \mathrm{Mt}^{\left.-\mathrm{CK}^{-/-(129 / \mathrm{B} 16)} ; \quad P=0.008\right) . \quad \mathrm{LV}}$ hypertrophy was less pronounced in females, but remained significant $(+17 \%$ versus C57BL/6; $P<0.05)$. Echocardiography showed that male $\mathrm{M} / \mathrm{Mt}-\mathrm{CK}^{-1-(129 / \mathrm{B} 16)}$ mice had $\mathrm{a}+16 \%$ larger cavity cross-sectional area during diastole indicating significant LV dilatation (Fig. 1b), exhibited contractile dysfunction $\left(\mathrm{d} P / \mathrm{d} t_{\max }-31 \%\right)$, end-diastolic pressures elevated 4.6-fold and significant pulmonary congestion compared with control mice (Fig. 1c-e), all indicative of congestive heart failure (see supplemental data table 1 for detailed analysis). In female mice, there were clear trends towards LV dysfunction for all these parameters, but differences were not statistically significant (Table 1).

In vivo haemodynamics in 1-year-old CK knockout mice on a pure C57BL/6 background

All subsequent experiments were obtained in $\mathrm{M}-\mathrm{CK}^{-1-}$ and $\mathrm{M} / \mathrm{Mt}^{-\mathrm{CK}^{-1-}}$ mice that were backcrossed in our laboratory with C57BL/6 stock mice for $>10$ generations. Comparisons were made with a single wild-type littermate
Table 1 Morphometry and in vivo cardiac function in 1-yearold female mice on a mixed genetic background
Values are mean \pm standard deviation, with $P$ values for unpaired Student's $t$ test

\begin{tabular}{|c|c|c|c|}
\hline Females & C57BL/6 & $\mathrm{M} / \mathrm{Mt}-\mathrm{CK}^{-/-}(129 / \mathrm{B} 16)$ & $P$ \\
\hline Morphometric parameters & $n=6$ & $n=6$ & \\
\hline Age (weeks) & $58 \pm 2$ & $56 \pm 8$ & 0.57 \\
\hline Body weight $(\mathrm{g})$ & $30 \pm 4$ & $28 \pm 4$ & 0.55 \\
\hline Tibial length (mm) & $18.4 \pm 0.4$ & $19.0 \pm 0.4$ & 0.02 \\
\hline LV weight (mg) & $80 \pm 6$ & $94 \pm 14$ & 0.048 \\
\hline RV weight (mg) & $21 \pm 2$ & $23 \pm 4$ & 0.31 \\
\hline Lung weight (mg) & $144 \pm 9$ & $159 \pm 16$ & 0.07 \\
\hline Liver weight $(\mathrm{g})$ & $1.158 \pm 0.125$ & $1.182 \pm 0.243$ & 0.83 \\
\hline Kidneys (mg) & $273 \pm 18$ & $368 \pm 56$ & 0.003 \\
\hline Haemodynamics & $n=6$ & $n=4$ & \\
\hline Aortic pressure—systolic (mmHg) & $96 \pm 5$ & $89 \pm 6$ & 0.09 \\
\hline Aortic pressure-diastolic (mmHg) & $65 \pm 6$ & $58 \pm 7$ & 0.13 \\
\hline Aortic pressure-mean $(\mathrm{mmHg})$ & $79 \pm 4$ & $74 \pm 6$ & 0.14 \\
\hline LV end-systolic pressure (mmHg) & $98 \pm 5$ & $92 \pm 7$ & 0.93 \\
\hline LV end-diastolic pressure ( $\mathrm{mmHg}$ ) & $4.8 \pm 2.9$ & $9.3 \pm 4$ & 0.08 \\
\hline $\mathrm{d} P / \mathrm{d} t_{\max }(\mathrm{mmHg} / \mathrm{s})$ & $8,684 \pm 1,526$ & $6,983 \pm 689$ & 0.07 \\
\hline $\mathrm{d} P / \mathrm{d} t_{\min }(\mathrm{mmHg} / \mathrm{s})$ & $-8,546 \pm 1,506$ & $-6,770 \pm 1,033$ & 0.08 \\
\hline Heart rate $(\mathrm{bpm})$ & $456 \pm 35$ & $441 \pm 18$ & 0.46 \\
\hline Echocardiography & $n=6$ & $n=6$ & \\
\hline End-diastolic area $\left(\mathrm{cm}^{2}\right)$ & $0.095 \pm 0.012$ & $0.101 \pm 0.013$ & 0.42 \\
\hline End-systolic area $\left(\mathrm{cm}^{2}\right)$ & $0.042 \pm 0.014$ & $0.041 \pm 0.013$ & 0.92 \\
\hline Fractional area change ( $\%)$ & $57 \pm 10$ & $59 \pm 11$ & 0.69 \\
\hline Myocardial cross-sectional area $\left(\mathrm{cm}^{2}\right)$ & $0.102 \pm 0.017$ & $0.135 \pm 0.011$ & 0.002 \\
\hline
\end{tabular}


Table 2 Enzyme activities in left ventricular tissue from ${\mathrm{M}-\mathrm{CK}^{-1-}}^{-}$ and $\mathrm{M} / \mathrm{Mt}^{-\mathrm{CK}^{-/-}}$mice on a pure $\mathrm{C} 57 \mathrm{BL} / 6 \mathrm{~J}$ genetic background

\begin{tabular}{llll}
\hline $\begin{array}{l}\text { Enzyme } \\
\text { activity } \\
\begin{array}{c}\text { (IU/mg } \\
\text { protein) }\end{array}\end{array}$ & $\begin{array}{l}\text { WT } \\
n=11\end{array}$ & $\begin{array}{l}\mathrm{M}^{-\mathrm{CK}^{-/-}} \\
n=10\end{array}$ & $\begin{array}{l}\mathrm{M} / \mathrm{Mt}-\mathrm{CK}^{-/-} \\
n=9\end{array}$ \\
\hline Total CK & $5.7 \pm 0.8$ & $1.9 \pm 0.3^{\dagger}$ & $0.12 \pm 0.02^{\dagger \#}$ \\
Mt-CK & $2.3 \pm 0.4$ & $1.8 \pm 0.3^{*}$ & 0 \\
MM-CK & $3.1 \pm 0.4$ & 0 & 0 \\
MB-CK & $0.18 \pm 0.06$ & 0 & 0 \\
BB-CK & $0.06 \pm 0.02$ & $0.08 \pm 0.01^{*}$ & $0.12 \pm 0.02^{\dagger \#}$ \\
$\begin{array}{c}\text { Total } \\
\text { adenylate }\end{array}$ & $2.4 \pm 0.5(12)$ & $2.4 \pm 0.1(5)$ & $2.2 \pm 0.8(9)$ \\
kinase & & & \\
Citrate & $0.88 \pm 0.18(12)$ & $0.86 \pm 0.12(12)$ & $0.77 \pm 0.20(12)$ \\
synthase & & & \\
\hline
\end{tabular}

Mean \pm standard deviation

Number of samples is indicated in the headings except where included in parenthesis

* Denotes $P<0.05{ }^{*} P<0.001$ and ${ }^{\dagger} P<0.0001$ compared to wild type. ${ }^{\#}$ Denotes $P<0.001$ for $\mathrm{M}-\mathrm{CK}^{-/-}$versus $\mathrm{M} / \mathrm{Mt}^{-\mathrm{CK}^{-1-}}$

control group. Measurement of protein activity in LV homogenates confirmed loss of target genes, resulting in

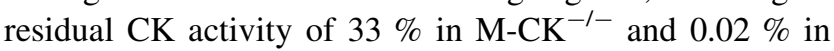
$\mathrm{M} / \mathrm{Mt}^{-\mathrm{CK}^{-1-}}$ mice. There was an increase in BB-CK iso-

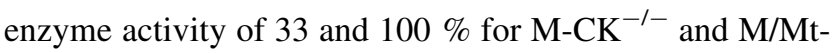
$\mathrm{CK}^{-1-}$ hearts, respectively (Table 2), but as this represents only $2 \%$ of normal total CK activity; however, the significance is unclear. There were no compensatory changes in either adenylate kinase or citrate synthase activities. Total LV creatine levels were indistinguishable from wild type $(P=0.46)$.

There were no significant differences between male and female mice for haemodynamic parameters when compared within genotypes, and therefore both sexes were analysed together. However, a detailed breakdown of these parameters for males and females is provided in supplemental data tables 2 and 3, respectively. Total animal numbers and sex ratios were: WT $n=26(12 \mathrm{M} / 14 \mathrm{~F})$, M-CK ${ }^{-1-} n=31(14 \mathrm{M} / 17 \mathrm{~F})$ and M/Mt-CK ${ }^{-1-} n=30$ $(12 \mathrm{M} / 18 \mathrm{~F})$. Mean age was 55 weeks in all groups (range 52-59 weeks).

Haemodynamic parameters were indistinguishable

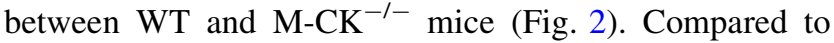
wild-type littermates, $\mathrm{M} / \mathrm{Mt}^{-\mathrm{CK}^{-1-}}$ mice had normal LV end-systolic and end-diastolic pressures (Fig. 2a, b), but had significantly impaired indices of relaxation $\left(\mathrm{d} P / \mathrm{d} t_{\min }\right.$ $31 \%$ lower and tau $31 \%$ longer than WT; Fig. 2c, d) and contraction $\left(\mathrm{d} P / \mathrm{d} t_{\max } 23 \%\right.$ lower than WT; Fig. $\left.2 \mathrm{~g}\right)$. Resting heart rate was also significantly lower than WT (10\%; Fig. 2e). Under conditions of maximal $\beta$-adrenergic stimulation using dobutamine infusion, both maximum heart rate and $\mathrm{d} P / \mathrm{d} t_{\max }$ increased in $\mathrm{M} / \mathrm{Mt}_{-} \mathrm{CK}^{-1-}$ mice, but remained significantly impaired compared to WT (11 and $24 \%$ lower, respectively; Fig. 2f, h). Thus, the relative differences in absolute values were maintained, but all groups showed similar contractile reserve as a percentage of resting baseline values, i.e. increasing $\mathrm{d} P / \mathrm{d} t_{\max }$ from baseline by $27 \%$ (Fig. 2i).

The lower heart rate in $\mathrm{M} / \mathrm{Mt}-\mathrm{CK}^{-1-}$ mice may account for some (or all) of the difference observed in contractility, i.e. by occupying different positions on the force-frequency response curve. To investigate this further, $\mathrm{d} P /$ $\mathrm{d} t_{\max }$ was correlated with heart rate (Fig. $2 \mathrm{j}$ ) for both genotypes: WT Pearson $r=0.61, P=0.001$; M/Mt$\mathrm{CK}^{-1-}$ Pearson $r=0.84, P<0.0001$. A runs test indicated that neither relationship deviated significantly from linearity; therefore, linear regression analysis was used to compare WT with M/Mt-CK ${ }^{-1-}$. Equation of line for WT was $y=21.3 x-1,562$ and for M/Mt-CK ${ }^{-1-} y=18.3 x-$ 1,273 . There was no difference in the slopes $(P=0.58)$, but the difference in elevation was highly significant $(P=0.0004)$, indicating that WT and M/Mt- $\mathrm{CK}^{-1-}$ hearts do not share the same relationship for $\mathrm{d} P / \mathrm{d} t_{\max }$ versus heart rate, but instead run in parallel (i.e. for any given heart rate, $\mathrm{d} P / \mathrm{d} t_{\max }$ is lower in $\mathrm{M} / \mathrm{Mt}-\mathrm{CK}^{-1-}$ hearts).

Echocardiographic examination of $\mathrm{M} / \mathrm{Mt}^{-} \mathrm{CK}^{-/-}$mice on the pure genetic background did not reveal any difference in cardiac volumes or in ejection fraction and cardiac output (Table 3). Pulmonary artery acceleration and ejection times were not different suggesting normal RV function and absence of pulmonary congestion. Transmitral Doppler was also indistinguishable from wild-type littermates suggesting that LV compliance was unaltered (Table 3).

Absence of LV hypertrophy on a pure C57BL/6 background

Postmortem LV weight was not elevated in either $\mathrm{M}-\mathrm{CK}^{-1-}$ or $\mathrm{M} / \mathrm{Mt}^{-} \mathrm{CK}^{-1-}$ mice, but body weight was $37 \%$ lower in $\mathrm{M} / \mathrm{Mt}^{-\mathrm{CK}^{-1}}$ mice, resulting in a high $\mathrm{LV} /$ body weight ratio (Fig. 3a-c). However, LV weight was in proportion to tibial length and to other major organs such as liver, kidneys, lungs and total heart weight (Fig. 3d-h). The same pattern was observed in both males and females when analysed separately (see supplemental data tables 2 and 3). An absence of LVH was confirmed on a molecular level by quantitative real-time RT-PCR to measure mRNA expression of common hypertrophy markers, which were not up-regulated (Fig. 4). Surprisingly, $\alpha$-skeletal actin was elevated in $\mathrm{M}-\mathrm{CK}^{-1-}$ compared to WT littermate controls; however, such a change in isolation does not suggest hypertrophy. 
Fig. 2 Left ventricular in vivo haemodynamics at 1 year of age in wild-type $(n=26)$,

${\mathrm{M}-\mathrm{CK}^{-\prime-}}^{-1}(n=31)$ and M/Mt$\mathrm{CK}^{-1-}(n=30)$ mice on a pure C57BL/6 genetic background. a, b There were no significant differences in LV end-systolic (LVSP) and end-diastolic pressure (LVEDP),

respectively; c, d diastolic function was impaired in M/Mt$\mathrm{CK}^{-1-}$ hearts for both maximal rate of pressure drop $\left(\mathrm{d} P / \mathrm{d} t_{\min }\right)$ and isovolumetric constant of relaxation (tau). e, f Heart rate was significantly lower in $\mathrm{M} / \mathrm{Mt}_{-} \mathrm{CK}^{-1-}$ hearts, both at baseline and under maximal $\beta$-adrenergic stimulation (16 ng/g Bwt/min dobutamine). $(\mathbf{g}, \mathbf{h})$ Likewise, contractility was impaired as measured by maximal rate of pressure development $\left(\mathrm{d} P / \mathrm{d} t_{\max }\right)$ at baseline and with dobutamine infusion, but not when measured as percentage change from baseline values (i). $\mathbf{j}$ There was a positive correlation between contractility $\left(\mathrm{d} P / \mathrm{d} t_{\text {max }}\right)$ and heart rate for both WT and $\mathrm{M} /{\mathrm{Mt}-\mathrm{CK}^{-1-}}^{-1}$ mice $(r=0.61$, $P=0.001$ and $r=0.84$, $P<0.0001$ respectively). Linear regression analysis indicated no difference between slopes, but significantly different intercepts

$(P=0.0004)$, suggesting that impaired contractility in M/Mt$\mathrm{CK}^{-1-}$ mice was not secondary to lower heart rate. Mean $\pm \mathrm{SD}$; comparison by one-way ANOVA with Bonferroni correction for multiple comparisons; $*$ denotes $P<0.05, * * P<0.01$ and $* * * P<0.001$
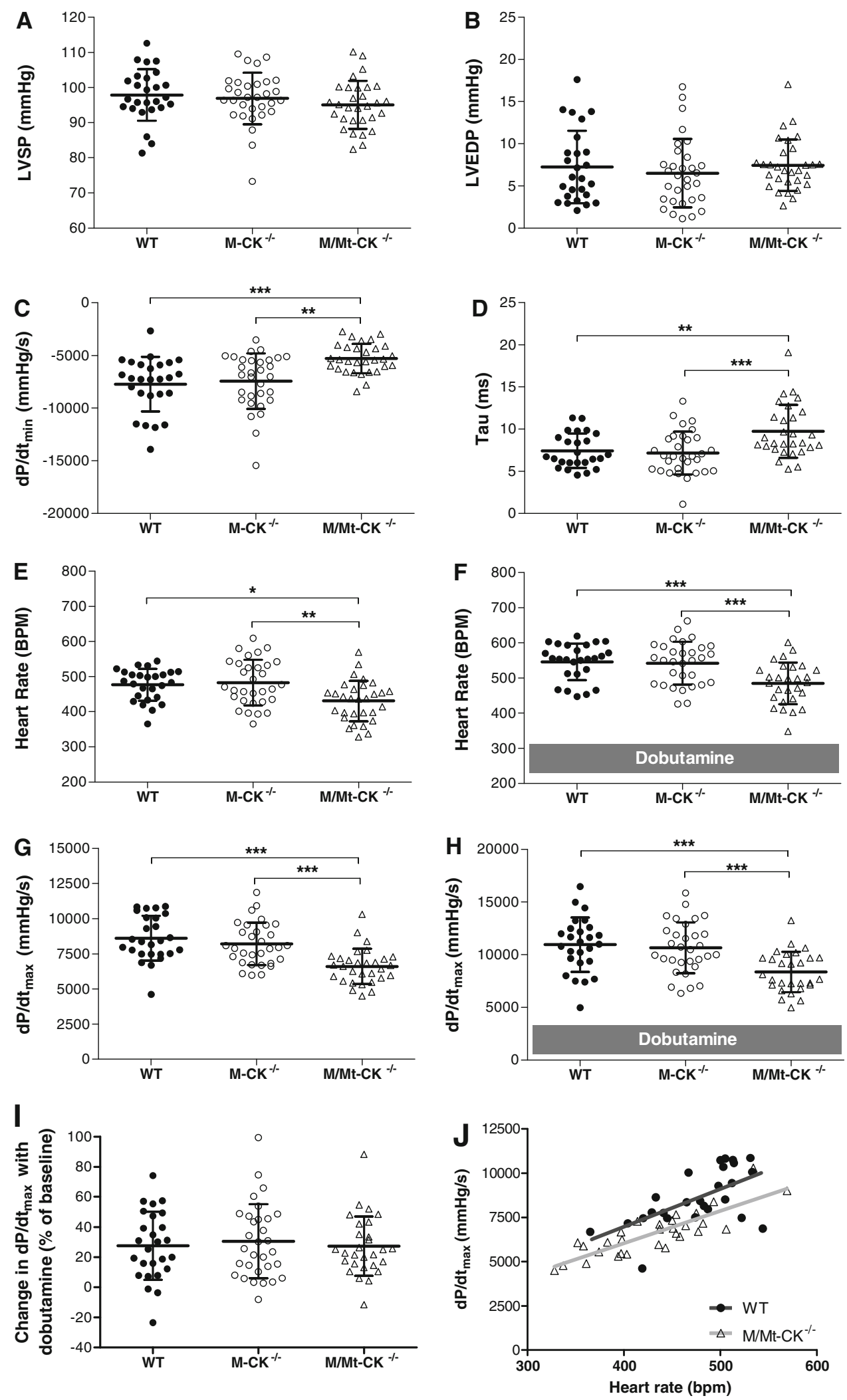
Table 3 Echocardiography at 1 year of age in male $\mathrm{M} / \mathrm{Mt}^{-\mathrm{CK}^{-1-}}$ mice on a pure C57BL/6J genetic background

\begin{tabular}{|c|c|c|c|}
\hline & WT & $\mathrm{M} / \mathrm{Mt}^{-\mathrm{CK}^{-/-}}$ & $P$ \\
\hline $\begin{array}{l}\text { Left ventricular } \\
\text { parameters }\end{array}$ & $n=6(4 \mathrm{M} / 2 \mathrm{~F})$ & $n=9(6 \mathrm{M} / 3 \mathrm{~F})$ & \\
\hline Heart rate (bpm) & $493 \pm 39$ & $493 \pm 46$ & 0.98 \\
\hline $\begin{array}{l}\text { End-diastolic volume } \\
\qquad(\mu \mathrm{l})\end{array}$ & $62 \pm 14$ & $61 \pm 15$ & 0.94 \\
\hline $\begin{array}{l}\text { End-systolic volume } \\
(\mu \mathrm{l})\end{array}$ & $29 \pm 8$ & $27 \pm 11$ & 0.80 \\
\hline Stroke volume $(\mu \mathrm{l})$ & $33 \pm 10$ & $34 \pm 8$ & 0.87 \\
\hline Cardiac output (ml/min) & $16.2 \pm 4.3$ & $16.7 \pm 4.6$ & 0.83 \\
\hline Ejection fraction (\%) & $53 \pm 7$ & $56 \pm 9$ & 0.58 \\
\hline Wall thickness (mm) & $0.90 \pm 0.05$ & $0.93 \pm 0.07$ & 0.34 \\
\hline \multicolumn{4}{|l|}{$\begin{array}{l}\text { Pulmonary artery } \\
\text { Doppler }\end{array}$} \\
\hline $\begin{array}{l}\text { PAT—acceleration } \\
\text { time }(\mathrm{ms})\end{array}$ & $21 \pm 3$ & $21 \pm 4$ & 0.7 \\
\hline $\begin{array}{l}\text { PET_-ejection time } \\
(\mathrm{ms})\end{array}$ & $60 \pm 8$ & $57 \pm 7$ & 0.45 \\
\hline PAT/PET & $0.36 \pm 0.04$ & $0.36 \pm 0.04$ & 0.87 \\
\hline \multicolumn{4}{|l|}{ Transmitral Doppler } \\
\hline E wave $(\mathrm{mm} / \mathrm{s})$ & $543 \pm 168$ & $660 \pm 201$ & 0.32 \\
\hline A wave $(\mathrm{mm} / \mathrm{s})$ & $358 \pm 143$ & $381 \pm 157$ & 0.80 \\
\hline $\mathrm{E} / \mathrm{A}$ & $1.6 \pm 0.5$ & $1.8 \pm 0.3$ & 0.41 \\
\hline
\end{tabular}

Values are mean \pm standard deviation, with $P$ values for unpaired Student's $t$ test

\section{Body composition}

Differences in body weight were investigated further by magnetic resonance relaxometry in $\mathrm{WT}$ and $\mathrm{M} / \mathrm{Mt}-\mathrm{CK}^{-1-}$
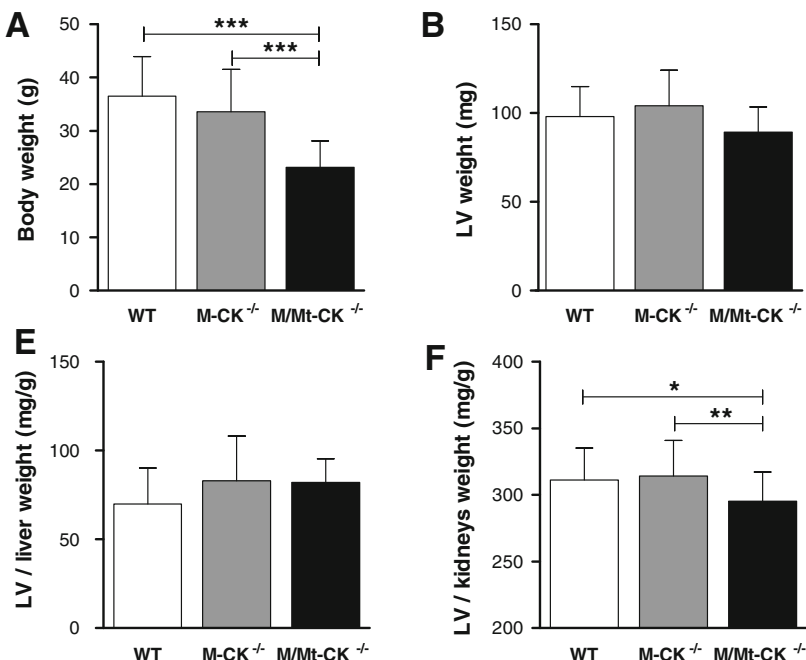

Fig. 3 Analysis of postmortem left ventricular (LV) weight at 1 year of age in wild-type $(n=26), \mathrm{M}_{-}-\mathrm{CK}^{-1-}(n=31)$ and $\mathrm{M} / \mathrm{Mt}-\mathrm{CK}^{-1-}$ $(n=30)$ mice on a pure C57BL/6 genetic background. (a) Body weight is significantly lower in $\mathrm{M} / \mathrm{Mt}^{-} \mathrm{CK}^{-1-}$ mice, but with normal absolute LV weight (b), this results in a higher LV/body weight ratio mice. As suggested by organ weight analysis, differences in body weights were driven by altered body composition and in particular by drastically reduced fat in $\mathrm{M} / \mathrm{Mt}-\mathrm{CK}^{-/-}$ mice. This was accompanied to a lesser extent by lower total body water and lean weight (Fig. 5a-e). These highly significant differences were observed in both male and female mice (supplemental data table 4). There was a linear relationship between percentage body fat and body water for both WT and $\mathrm{M} / \mathrm{Mt}-\mathrm{CK}^{-1-}$ mice that was indistinguishable, suggesting that they are at different ends of the same continuum (Fig. 5e).

\section{Discussion}

In this study, we show that the in vivo phenotype is highly dependent on genetic background, gender and age, and that there are major changes to body weight and composition. Previous reports of CK knockout mice have utilised strains on a mixed, non-fixed, genetic background, have seldom reported male-to-female ratios, and have not looked beyond 41 weeks of age. These variables are likely to explain why reports in this strain, for example relating to LV hypertrophy, have at times been contradictory.

Male $\mathrm{M} / \mathrm{Mt}^{-\mathrm{CK}^{-/-}}$on a mixed genetic background develop heart failure

M/Mt-CK ${ }^{-1-(129 / B 16)}$ mice (i.e. on a standard mixed background) have previously been studied up to 41 weeks of age, at which point they had extensive LVH, mild dilatation and normal ejection fraction by MRI [16, 17]. We have
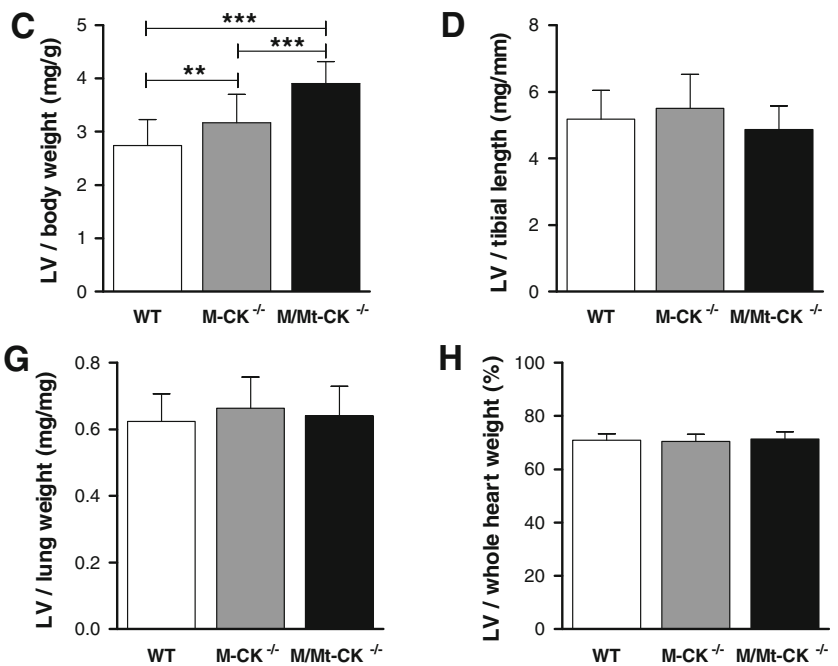

(c). However, this difference is driven by changes in body composition affecting body weight, since LV weight is not elevated when compared with tibial length (d), or other major organs such as liver (e), kidneys (f) and lung (g) and as percentage of whole heart weight (h). Mean $\pm \mathrm{SD}$; $*$ denotes $P<0.05, * * P<0.01$ and $* * * P<0.001$ 
Fig. 4 Relative gene expression of hypertrophy markers in left ventricular tissue from 1-year-old wild-type,

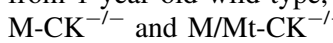
mice on a pure C57BL/6 genetic background $(n=3$ male $+n=3$ female of each genotype). ANP atrial natriuretic peptide, $B N P$ brain natriuretic peptide, $\beta-M H C$ $\beta$-myosin heavy chain. Mean $\pm \mathrm{SD}$; * denotes $P<0.01$

Fig. 5 Body composition analysis by magnetic resonance relaxometry at 1 -year of age in wild-type $(n=11)$ and M/Mt$\mathrm{CK}^{-/-}(n=14)$ mice on a pure C57BL/6 genetic background. Body weight (a); total body fat (b); total body water (c); lean weight (d). The relationship between percentage body fat and percentage body water was preserved in $\mathrm{M} / \mathrm{Mt}-\mathrm{CK}^{-1-}$ mice with a linear relationship indistinguishable from wild type. Mean $\pm \mathrm{SD}$; $* *$ denotes $P<0.01$ and $* * * P<0.001$
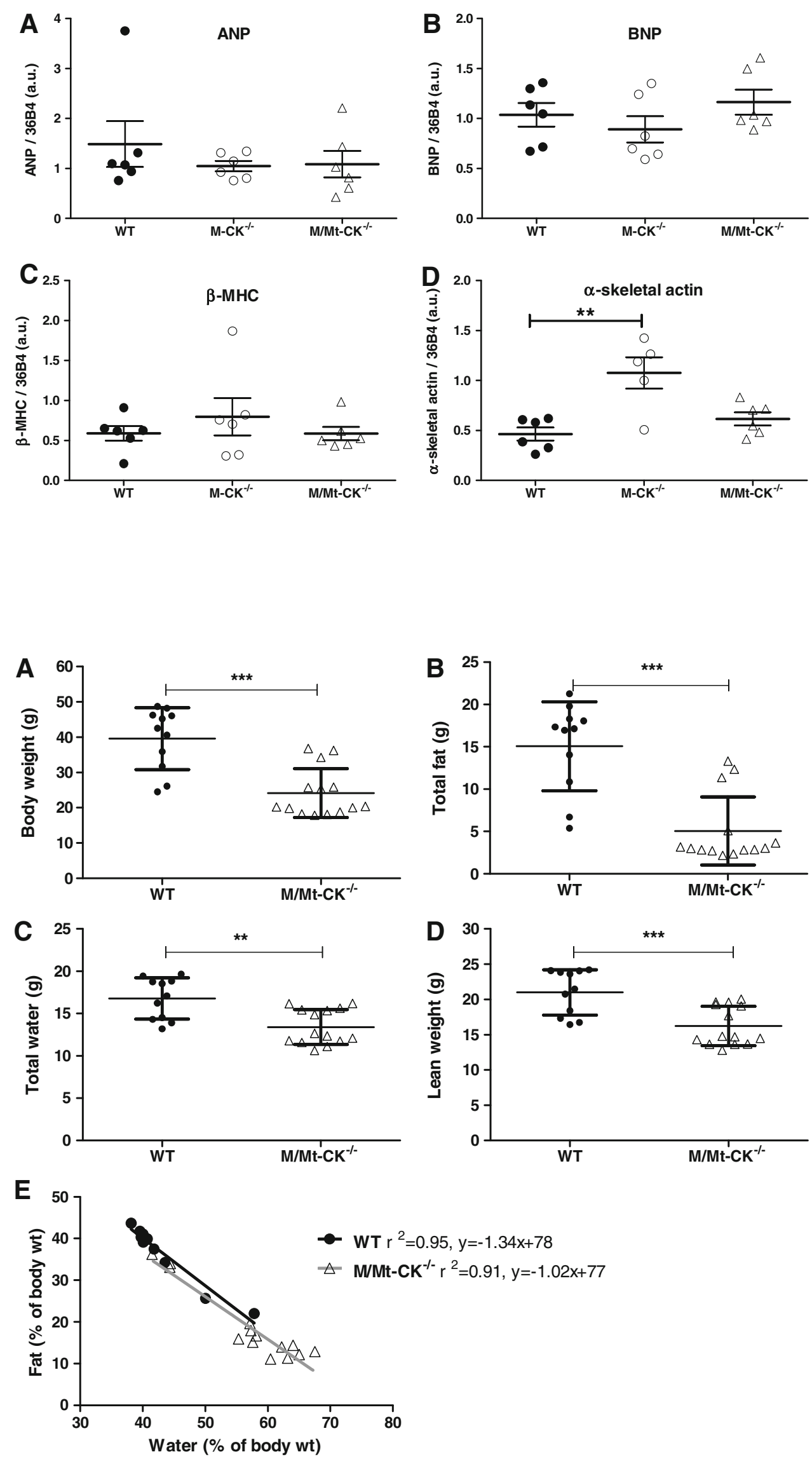
now demonstrated that at 1 year of age this compensated hypertrophy eventually progresses to heart failure, but only in males, with females much less severely affected. Since previous studies have used stock C57BL/6 as a control for

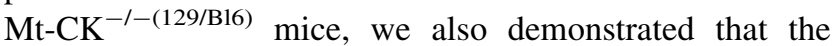
choice of control, whether C57BL/6 or $129 \mathrm{~Sv}$, does not affect the extent of LVH observed. Previous studies measured cardiac function using MRI, and in our experience it is not unusual to find minimal differences in global imaging parameters, yet still observe large differences in LV pressures. For example, we have previously shown that creatine-deficient mice have normal ejection fraction, but impaired pressure-generating capacity [26]. This should not be surprising, as these parameters report very different phases in the cardiac cycle.

Creatine kinase-deficient mice survive for a long time with only mild dysfunction, so obviously CK activity is not obligatory for cardiac function, but the finding that male

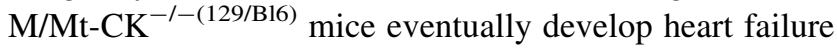
suggests that loss of CK places a chronic strain on the heart and that gender modulates the effects of CK depletion. Multiple changes have been described in the ageing heart that impact on its ability to tolerate stress [5], and this may result in the gradual unmasking of the functional phenotype over time. A wide range of potentially compensatory adaptations have been described in $\mathrm{M} / \mathrm{Mt}^{-} \mathrm{CK}^{-/-(129 / \mathrm{Bl6})}$ mice to explain the mild early phenotype, for example, closer juxtaposition of mitochondria with myofilaments, thereby reducing diffusion distance [13], coupling of glycolysis with the SERCA pump [4] and increased mitochondrial capacity with flux through alternative phosphotransfer pathways [9]. It may be that these changes are inefficient or energy costly and therefore cannot be maintained as a compensatory mechanism in the long term. This also suggests that reduced CK activity, as occurs in the failing heart [14] and in viral myocarditis [10], may indeed contribute to disease progression. Although CK dysfunction is not as severe as in the double knockout, the effect is likely to be amplified when overlaid on existing organic disease and in combination with gross changes in cellular processes, inflammation and neuro-endocrine signalling.

$\mathrm{M} / \mathrm{Mt}^{-\mathrm{CK}^{-1-}}$ on a pure genetic background have a milder cardiac phenotype

We have previously shown that genetic background has a major effect on the phenotype of Mt- $\mathrm{CK}^{-1-}$ mice [15]. We therefore backcrossed $\mathrm{M}-\mathrm{CK}^{-1-}$ and $\mathrm{M} / \mathrm{Mt}^{-\mathrm{CK}^{-1-}}$ lines until they were congenic with C57BL/6 mice (theoretically $99.9 \%$ identical). This did not alter the phenotype in $\mathrm{M}-\mathrm{CK}^{-1-}$ mice, which remained mild to non-existent even when studied at 1-year of age. However, M/Mt-CK ${ }^{-/-}$ mice had a less severe phenotype compared to M/Mt$\mathrm{CK}^{-/-(129 / \mathrm{Bl} 6)}$; most notably, they had normal end-diastolic pressure and an absence of LVH and pulmonary congestion. It is likely that this disparity purely reflects genetic differences rather than environmental or experimental influences such as diet or pathogen status, since M/Mt$\mathrm{CK}^{-1-(129 / B 16)}$ obtained from Würzburg but kept in our laboratory developed LV hypertrophy as expected. Clearly, the backcrossed mice are no longer in heart failure, which suggests the existence of powerful genetic modifiers in the C57BL/6 background to account for this. Future identification of these modifiers may suggest therapeutic targets for heart failure.

A lack of LVH is in agreement with our previous find-

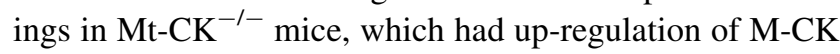
and citrate synthase as potential compensatory pathways [15]. We predicted that backcrossed $\mathrm{M} / \mathrm{Mt}-\mathrm{CK}^{-/-}$mice would therefore have a more pronounced phenotype, since they have no M-CK with which to compensate with. This does appear to be the case since backcrossed M/Mt-CK ${ }^{-/-}$ had impaired indices of isovolumetric function that were not observed in $\mathrm{Mt}-\mathrm{CK}^{-1-}$ mice at the same age. A potential compensatory role for increased mitochondrial capacity (as suggested by elevated citrate synthase) was observed in our backcrossed $\mathrm{Mt}-\mathrm{CK}^{-1-}$ mice [15] and also recently in the M/Mt-CK ${ }^{-/-(129 / B 16)}$ strain [9]. However, we did not observe an increase in citrate synthase activity in our backcrossed $\mathrm{M} / \mathrm{Mt}-\mathrm{CK}^{-1-}$ strain even though they had a milder phenotype, which argues against a compensatory role.

Genetic background and the choice of control

It is increasingly recognised that genetic background can have a major influence on observed phenotypes in terms of both normal cardiac function [8,31] and response to pathological stress [3], and we have previously shown this to be true for $\mathrm{Mt}-\mathrm{CK}^{-1-}$ mice [15]. This underlines the importance of using appropriate controls in mouse studies. The optimal control for a double knockout mouse is to use heterozygous mating to produce double WT littermates for comparison, and this is the approach we took for the mice on a pure C57BL/6 background. This would also be optimal for mice on a non-fixed, mixed background, even though random mixing will mean that wild-type mice are not genetically identical. However, we chose to use stock C57BL/6 as controls for the experiments on $\mathrm{M} / \mathrm{Mt}_{-} \mathrm{CK}^{-1-}$ ${ }^{(129 / B 16)}$ mice, because we wanted to emulate the conditions used in previous studies to determine whether we could recapitulate their findings. The limitations of using a poor control in those studies are therefore shared by our experiments on $\mathrm{M} / \mathrm{Mt}^{-\mathrm{CK}^{-/-(129 / \mathrm{B} 16)} \text { mice. }}$ 
Whole body phenotype

An unexpected finding, not previously described in the literature, was lower body weight observed in $\mathrm{M} / \mathrm{Mt}^{-} \mathrm{CK}^{-/-}$ mice regardless of genetic background (although not in

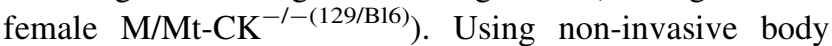
composition analysis, we established that this was mainly driven by reduced body fat in knockout mice. Water content was also reduced in $\mathrm{M} / \mathrm{Mt}_{-} \mathrm{CK}^{-1-}$ mice; however, water is linearly related to fat over a wide range of body compositions in the mouse [6], therefore the preservation of the fatto-water relationship suggests that this change is secondary to alterations in fat content. Although less pronounced, this pattern is very similar to creatine-free (GAMT knockout) mice [23] and indicates that disruption of the CK system has profound effects on whole body metabolism.

\section{Conclusions}

Mice with chronic deficiency of both muscle- and mitochondrial-creatine kinase develop compensated LV hypertrophy that eventually progresses to congestive heart failure. The extent of this phenotype is highly dependent on genetic background, gender and age. That a primary defect in the creatine kinase system can, in itself, result in heart failure lends credence to the hypothesis that impaired CK activity observed in the failing heart may contribute to disease progression and is therefore a target for therapeutic intervention.

Acknowledgments This work was funded by the British Heart Foundation programme grant RG/10/002/28187. Additional funding for the Visualsonics ultrasound system was provided by the BHF Centre of Research Excellence, Oxford (RE/08/004); for the EchoMRI Body Composition Analyser by the OUP John Fell Fund; and from a Wellcome Trust Core Award, Grant (090532/Z/09/Z). Knockout mice were originally generated and gifted by Prof Bé Wieringa, Department of Cell Biology, Nijmegen Centre for Molecular Life Sciences, Radboud University Medical Centre, Nijmegen, The Netherlands.

Conflict of interest The authors declare that they have no conflict of interest.

Open Access This article is distributed under the terms of the Creative Commons Attribution License which permits any use, distribution, and reproduction in any medium, provided the original author(s) and the source are credited.

\section{References}

1. Aksentijevic D, Lygate CA, Makinen K, Zervou S, SebagMontefiore L, Medway D, Barnes H, Schneider JE, Neubauer S (2010) High-energy phosphotransfer in the failing mouse heart: role of adenylate kinase and glycolytic enzymes. Eur J Heart Fail 12:1282-1289. doi:10.1093/eurjhf/hfq174
2. Barbaric I, Miller G, Dear TN (2007) Appearances can be deceiving: phenotypes of knockout mice. Brief Funct Genom Proteom 6:91-103. doi:10.1093/bfgp/elm008

3. Barrick CJ, Rojas M, Schoonhoven R, Smyth SS, Threadgill DW (2007) Cardiac response to pressure overload in 129S1/SvImJ and C57BL/6J mice: temporal- and background-dependent development of concentric left ventricular hypertrophy. Am J Physiol Heart Circ Physiol 292:H2119-H2130. doi:10.1152/ ajpheart.00816.2006

4. Boehm E, Ventura-Clapier R, Mateo P, Lechene P, Veksler V (2000) Glycolysis supports calcium uptake by the sarcoplasmic reticulum in skinned ventricular fibres of mice deficient in mitochondrial and cytosolic creatine kinase. J Mol Cell Cardiol 32:891-902. doi:10.1006/jmcc.2000.1130

5. Boengler K, Schulz R, Heusch G (2009) Loss of cardioprotection with ageing. Cardiovasc Res 83:247-261. doi:10.1093/cvr/ cvp033

6. Cox JE, Laughton WB, Powley TL (1985) Precise estimation of carcass fat from total body water in rats and mice. Physiol Behav 35:905-910. doi:10.1016/0031-9384(85)90258-6

7. Crozatier B, Badoual T, Boehm E, Ennezat PV, Guenoun T, Su J, Veksler V, Hittinger L, Ventura-Clapier R (2002) Role of creatine kinase in cardiac excitation-contraction coupling: studies in creatine kinase-deficient mice. FASEB J 16:653-660. doi: 10.1096/fj.01-0652com

8. Deschepper CF, Olson JL, Otis M, Gallo-Payet N (2004) Characterization of blood pressure and morphological traits in cardiovascular-related organs in 13 different inbred mouse strains. J Appl Physiol 97:369-376. doi:10.1152/japplphysiol.00073. 2004

9. Dzeja PP, Hoyer K, Tian R, Zhang S, Nemutlu E, Spindler M, Ingwall JS (2011) Rearrangement of energetic and substrate utilization networks compensate for chronic myocardial creatine kinase deficiency. J Physiol 589:5193-5211. doi:10.1113/jphysiol. 2011.212829

10. Ebermann L, Piper C, Kuhl U, Klingel K, Schlattner U, Siafarikas N, Zeichhardt H, Schultheiss HP, Dorner A (2009) Impact of myocardial inflammation on cytosolic and mitochondrial creatine kinase activity and expression. Basic Res Cardiol 104:247-257. doi:10.1007/s00395-008-0773-5

11. Gupta A, Akki A, Wang Y, Leppo MK, Chacko VP, Foster DB, Caceres V, Shi S, Kirk JA, Su J, Lai S, Paolocci N, Steenbergen C, Gerstenblith G, Weiss RG (2012) Creatine kinase-mediated improvement of function in failing mouse hearts provides causal evidence the failing heart is energy starved. J Clin Invest 122:291-302. doi:10.1172/Jci57426

12. Ingwall JS, Weiss RG (2004) Is the failing heart energy starved? On using chemical energy to support cardiac function. Circ Res 95:135-145. doi:10.1161/01.RES.0000137170.41939.d9

13. Kaasik A, Veksler V, Boehm E, Novotova M, Minajeva A, Ventura-Clapier R (2001) Energetic crosstalk between organelles: architectural integration of energy production and utilization. Circ Res 89:153-159. doi:10.1161/hh1401.093440

14. Lygate CA, Fischer A, Sebag-Montefiore L, Wallis J, Ten Hove M, Neubauer S (2007) The creatine kinase energy transport system in the failing mouse heart. J Mol Cell Cardiol 42:11291136. doi:10.1016/j.yjmcc.2007.03.899

15. Lygate CA, Hunyor I, Medway D, de Bono JP, Dawson D, Wallis J, Sebag-Montefiore L, Neubauer S (2009) Cardiac phenotype of mitochondrial creatine kinase knockout mice is modified on a pure C57BL/6 genetic background. J Mol Cell Cardiol 46:93-99. doi:10.1016/j.yjmcc.2008.09.710

16. Nahrendorf M, Spindler M, Hu K, Bauer L, Ritter O, Nordbeck P, Quaschning T, Hiller KH, Wallis J, Ertl G, Bauer WR, Neubauer S (2005) Creatine kinase knockout mice show left ventricular hypertrophy and dilatation, but unaltered remodeling post- 
myocardial infarction. Cardiovasc Res 65:419-427. doi:10.1016/ j.cardiores.2004.10.006

17. Nahrendorf M, Streif JU, Hiller KH, Hu K, Nordbeck P, Ritter O, Sosnovik DE, Bauer L, Neubauer S, Jakob PM, Ertl G, Spindler M, Bauer WR (2006) Multimodal functional cardiac MR imaging in creatine kinase deficient mice reveals subtle abnormalities in myocardial perfusion and mechanics. Am J Physiol Heart Circ Physiol 290:H2516-H2521. doi:10.1152/ajpheart.01038.2005

18. Nascimben L, Friedrich J, Liao R, Pauletto P, Pessina AC, Ingwall JS (1995) Enalapril treatment increases cardiac performance and energy reserve via the creatine kinase reaction in myocardium of Syrian myopathic hamsters with advanced heart failure. Circulation 91:1824-1833. doi:10.1161/01.CIR.91.6.1824

19. Neubauer S (2007) The failing heart-an engine out of fuel. N Engl J Med 356:1140-1151. doi:10.1056/NEJMra063052

20. Neubauer S, Horn M, Cramer M, Harre K, Newell JB, Peters W, Pabst T, Ertl G, Hahn D, Ingwall JS, Kochsiek K (1997) Myocardial phosphocreatine-to-ATP ratio is a predictor of mortality in patients with dilated cardiomyopathy. Circulation 96:21902196. doi:10.1161/01.CIR.96.7.2190

21. Neubauer S, Horn M, Naumann A, Tian R, Hu K, Laser M, Friedrich J, Gaudron P, Schnackerz K, Ingwall JS et al (1995) Impairment of energy metabolism in intact residual myocardium of rat hearts with chronic myocardial infarction. J Clin Invest 95:1092-1100. doi:10.1172/JCI117756

22. Saupe KW, Spindler M, Tian R, Ingwall JS (1998) Impaired cardiac energetics in mice lacking muscle-specific isoenzymes of creatine kinase. Circ Res 82:898-907. doi:10.1161/01.RES. 82.8.898

23. Schmidt A, Marescau B, Boehm EA, Renema WK, Peco R, Das A, Steinfeld R, Chan S, Wallis J, Davidoff M, Ullrich K, Waldschutz R, Heerschap A, De Deyn PP, Neubauer S, Isbrandt D (2004) Severely altered guanidino compound levels, disturbed body weight homeostasis and impaired fertility in a mouse model of guanidinoacetate N-methyltransferase (GAMT) deficiency. Hum Mol Genet 13:905-921. doi:10.1093/hmg/ddh112

24. Spindler M, Niebler R, Remkes H, Horn M, Lanz T, Neubauer S (2002) Mitochondrial creatine kinase is critically necessary for normal myocardial high-energy phosphate metabolism. Am J Physiol Heart Circ Physiol 283:H680-H687. doi:10.1152/ ajpheart.00800.2001
25. Steeghs K, Benders A, Oerlemans F, de Haan A, Heerschap A, Ruitenbeek W, Jost C, van Deursen J, Perryman B, Pette D, Bruckwilder M, Koudijs J, Jap P, Veerkamp J, Wieringa B (1997) Altered $\mathrm{Ca}^{2+}$ responses in muscles with combined mitochondrial and cytosolic creatine kinase deficiencies. Cell 89:93-103. doi: 10.1016/S0092-8674(00)80186-5

26. ten Hove M, Lygate CA, Fischer A, Schneider JE, Sang AE, Hulbert K, Sebag-Montefiore L, Watkins H, Clarke K, Isbrandt D, Wallis J, Neubauer S (2005) Reduced inotropic reserve and increased susceptibility to cardiac ischemia/reperfusion injury in phosphocreatine-deficient guanidinoacetate- $\mathrm{N}$-methyltransferaseknockout mice. Circulation 111:2477-2485. doi:10.1161/01.CIR. 0000165147.99592 .01

27. van Deursen J, Heerschap A, Oerlemans F, Ruitenbeek W, Jap P, ter Laak H, Wieringa B (1993) Skeletal muscles of mice deficient in muscle creatine kinase lack burst activity. Cell 74:621-631. doi:10.1016/0092-8674(93)90510-W

28. Van Dorsten FA, Nederhoff MG, Nicolay K, Van Echteld CJ (1998) 31P NMR studies of creatine kinase flux in M-creatine kinase-deficient mouse heart. Am J Physiol 275:H1191-H1199

29. Ventura-Clapier R, Garnier A, Veksler V (2004) Energy metabolism in heart failure. J Physiol 555:1-13. doi:10.1113/jphysiol. 2003.055095

30. Ventura-Clapier R, Kuznetsov AV, d'Albis A, van Deursen J, Wieringa B, Veksler VI (1995) Muscle creatine kinase-deficient mice. I. Alterations in myofibrillar function. J Biol Chem 270:19914-19920. doi:10.1074/jbc.270.34.19914

31. Waldeyer C, Fabritz L, Fortmueller L, Gerss J, Damke D, Blana A, Laakmann S, Kreienkamp N, Volkery D, Breithardt G, Kirchhof P (2009) Regional, age-dependent, and genotype-dependent differences in ventricular action potential duration and activation time in 410 Langendorff-perfused mouse hearts. Basic Res Cardiol 104:523-533. doi:10.1007/s00395-009-0019-1

32. Wyss M, Kaddurah-Daouk R (2000) Creatine and creatinine metabolism. Physiol Rev 80:1107-1213

33. Ye Y, Gong G, Ochiai K, Liu J, Zhang J (2001) High-energy phosphate metabolism and creatine kinase in failing hearts: a new porcine model. Circulation 103:1570-1576. doi:10.1161/01.CIR. 103.11.1570 